\title{
Comparison of Two Novel Solution-Based Routes for the Synthesis of Equiaxed ZnO Nanoparticles
}

\author{
K. Elen, ${ }^{1,2,3}$ A. Kelchtermans, ${ }^{1}$ H. Van den Rul, ${ }^{1,2}$ R. Peeters, ${ }^{3}$ J. Mullens, ${ }^{1}$ \\ A. Hardy, ${ }^{1,2}$ and M. K. Van Bael ${ }^{1,2}$ \\ ${ }^{1}$ Inorganic and Physical Chemistry, Institute for Materials Research, Hasselt University, Agoralaan Building D, \\ 3590 Diepenbeek, Belgium \\ ${ }^{2}$ Division Group IMOMEC, IMEC vzw, Agoralaan Building D, 3590 Diepenbeek, Belgium \\ ${ }^{3}$ VerpakkingsCentrum, XIOS Hogeschool Limburg, Agoralaan Building H, 3590 Diepenbeek, Belgium
}

Correspondence should be addressed to M. K. Van Bael, marlies.vanbael@uhasselt.be

Received 23 December 2010; Accepted 2 May 2011

Academic Editor: Rakesh Joshi

Copyright $\odot 2011 \mathrm{~K}$. Elen et al. This is an open access article distributed under the Creative Commons Attribution License, which permits unrestricted use, distribution, and reproduction in any medium, provided the original work is properly cited.

Due to a dominant one-dimensional growth rate, nanoparticles of zinc oxide often show a rodlike morphology. As a result, the synthesis of small spherical nanoparticles of undoped $\mathrm{ZnO}$ remains challenging. This paper presents two procedures that successfully produce a powder consisting of equiaxed zinc oxide nanoparticles: one using a polyethylene glycol- (PEG-) assisted solvothermal method and the other by calcination of zinc oxalate obtained from a microemulsion-mediated method. In the latter, zinc-substituted aerosol OT (AOT) is used as a surfactant. The samples are characterized by inductively coupled plasmaatomic emission spectroscopy (ICP-AES), thermogravimetric analysis (TGA), X-ray diffraction (XRD), Fourier transform infrared spectroscopy (FTIR), transmission electron microscopy (TEM), photon correlation spectroscopy (PCS), and photoluminescence (PL) spectroscopy. Both synthesis techniques produce nanoparticles with similar sizes in the range of 10 to $20 \mathrm{~nm}$. Dense aggregates observed in the calcined powder are infrequent in the case of the solvothermal method.

\section{Introduction}

Because of their unique properties, nanoparticles of zinc oxide play a central role in numerous technological applications [1-3]. $\mathrm{ZnO}$ is a known n-type semiconductor with a bandgap of $3.4 \mathrm{eV}$. As a result, the material absorbs UV light, and it is transparent to visible light. Furthermore, zinc oxide is biocompatible, and it exhibits both piezo- and pyroelectric properties. Combinations of these qualities allow that $\mathrm{ZnO}$ nanoparticles can be used in various technologies such as photovoltaics [4,5], electronics [6], and (photo) catalysts [7].

Working with spherical $\mathrm{ZnO}$ nanoparticles can have definite advantages. For example, the light scattering capabilities of particles are significantly reduced when they are smaller than $100 \mathrm{~nm}$ in all directions. This can be useful in applications, where the particles should be undetectable to the human eye. Nonetheless, $\mathrm{ZnO}$ nanoparticles often show an elongated morphology, owing to a dominant growth rate along the c-axis of the wurtzite crystal. As a result, the solution-based synthesis of spherical $\mathrm{ZnO}$ particles remains a challenging task, especially for particles with sizes below $50 \mathrm{~nm}$.

Solution-based methods for the synthesis of nanostructures are a valuable alternative to conventional processing and gas phase synthesis, with known commercial applications [8]. Moreover, they allow easy tailoring of synthesis parameters throughout the whole process, which may be utilized to achieve a more precise control of composition, shape, and size of the resulting materials $[9,10]$.

A promising but relatively unexplored solution-based strategy for the synthesis of spherical nanoparticles is by using a microemulsion-mediated method [11]. A microemulsion is a thermodynamically stable, transparent dispersion of two immiscible liquids, stabilized by an interfacial monomolecular layer of surfactant molecules [12]. A "water-in-oil" microemulsion consists of aqueous droplets (reversed micelles) dispersed in a continuous apolar phase. By using a microemulsion-mediated method, the reaction 
environment is restricted to the aqueous cores of the micelles that function both as nanoreactors and as soft templates [13]. The size as well as the shape of the micelles can be adjusted by carefully choosing the composition of the microemulsion. These properties make a microemulsion-mediated method ideal for the synthesis of equiaxial $\mathrm{ZnO}$ nanoparticles.

Traditionally, soluble metal salts are first incorporated in the aqueous cores of the micelles, followed by a precipitation. On the other hand, attaching the metal ions of the desired oxide to the head group of an anionic surfactant leads to certain advantages. Firstly, contamination by additional, undesirable counterions is prevented. Secondly, the modified surfactant acts both as metal source and microemulsion stabilizer [14]. And finally, it allows precise control over the stoichiometry for the synthesis of multimetal oxides, such as $\mathrm{BaFe}_{12} \mathrm{O}_{19}$ [15].

The solvothermal route is an alternative uncomplicated production method that ensures that large quantities of $\mathrm{ZnO}$ can be produced in a reasonable time and in an ecologically justifiable environment. However, $\mathrm{ZnO}$ shows a typical onedimensional growth along its crystal c-axis when using this wet chemical technique [16-18]. In order to suppress this distinctive 1D growth, several changes have to be made to the synthesis procedure. One possible strategy is the addition of organic molecules that adsorb to the surface of the growing particle and thus prevent further growth in one or more dimensions. Polyethylene glycol (PEG) is often used in procedures to obtain nanorods. Nevertheless, Li et al. [19] report that spherical nanoparticles can be obtained when using high concentrations of PEG. Other possibilities include the use of high temperatures and short reaction times. Also, a low $\mathrm{OH}^{-}: \mathrm{Zn}^{2+}$ ratio is advisory, as a study by Zhang and $\mathrm{Mu}[20]$ reveals that rod formation is promoted by high $\mathrm{OH}^{-}$ concentrations. Despite these studies, it remains difficult to find the exact conditions for the solvothermal synthesis of spherical $\mathrm{ZnO}$ nanoparticles in a specific system.

In this paper, novel procedures of the two above wet chemical techniques are applied for the synthesis of zinc oxide nanoparticles. Powders resulting from a microemulsion-mediated method and a solvothermal method are compared. For the microemulsion-mediated method, zinc-substituted aerosol OT $(=$ AOT $=$ dioctyl sulfosuccinate) is used as metal source and as microemulsion stabilizer. Special attention is given to the agglomeration behaviour of the particles obtained by the two methods.

\section{Materials and Methods}

2.1. Materials. In this study, the following chemicals are used: $\mathrm{Zn}\left(\mathrm{NO}_{3}\right)_{2} \cdot 6 \mathrm{H}_{2} \mathrm{O}$ (zinc nitrate hexahydrate, 98\%, Sigma Aldrich), Na(AOT) (dioctyl sulfosuccinate, sodium salt, 96\%, Acros), absolute ethanol (analytical reagent grade, Fisher Scientific), diethyl ether (98\%, Sigma Aldrich), n-heptane (p.a., Merck), diethyl oxalate (99\%, Sigma Aldrich), methanol (p.a., Acros), chloroform (99\%, Acros), acetone (general-purpose grade, Fisher Scientific), $\mathrm{Zn}\left(\mathrm{CH}_{3} \mathrm{COO}\right)_{2} \cdot 2 \mathrm{H}_{2} \mathrm{O}$ (zinc acetate dihydrate, ACS reagent, Acros), PEG-400 (polyethylene glycol 400, Alfa Aesar),
$\mathrm{NaOH}$ (sodium hydroxide, 98\%, Aldrich), $\mathrm{HNO}_{3}$ (nitric acid, 69-70\%, Baker Instra-analyzed Reagent, J.T. Baker), zinc AAS standard solution (specpure, Alfa Aesar), $\mathrm{KBr}$ (potassium bromide for IR spectroscopy, Merck), and deionized water (milliQ, resistivity 18.0 MOhm cm).

2.2. Preparation of Zinc-Substituted Aerosol OT. A modification of the procedure described by Eastoe et al. [21] is used for the replacement of sodium by zinc in Aerosol OT. $200 \mathrm{~mL}$ of a $5 \mathrm{M} \mathrm{Zn}\left(\mathrm{NO}_{3}\right)_{2}$ solution in water and $100 \mathrm{~mL}$ of a $1 \mathrm{MNa}(\mathrm{AOT})$ solution in ethanol are first heated to $60^{\circ} \mathrm{C}$ and then combined. As opposed to Eastoe's method, the resulting mixture is then stirred for $72 \mathrm{~h}$ at $60^{\circ} \mathrm{C}$. When cooled down, the mixture is transferred to a separating funnel, and $125 \mathrm{~mL}$ of diethyl ether is added. The lower phase, containing $\mathrm{NaNO}_{3}$, is removed, and the remaining organic phase is washed nine times with deionised water. The surfactant-containing phase is then evaporated on a Buchi rotari evaporator and stored for $24 \mathrm{~h}$ in a vacuum oven at $60^{\circ} \mathrm{C}$.

2.3. Microemulsion Synthesis of $\mathrm{ZnO}$ Nanoparticles. Two microemulsions are prepared by initially dissolving $5 \mathrm{~g}$ of $\mathrm{Zn}(\mathrm{AOT})_{2}$ in $20 \mathrm{~mL}$ of heptane. To the first solution, $0.5 \mathrm{~mL}$ of water is added, to the second solution, $1.5 \mathrm{~mL}$ of diethyl oxalate is added. After stabilization, both microemulsions are combined and stirred at $60^{\circ} \mathrm{C}$ for $2.5 \mathrm{~h}$. Zinc oxalate particles are recovered by the addition of $40 \mathrm{~mL}$ of acetone and subsequent centrifugation (Heraeus Sepatech Biofuge $28 \mathrm{RS}, 9400 \mathrm{rpm}, 10 \mathrm{~min}$ ). The obtained precipitate is washed three times with a $1: 1$ mixture of methanol: chloroform and three times with a $1: 1$ mixture of methanol:acetone. For further characterization, the oxalate precursor is dried for $24 \mathrm{~h}$ in an oven at $60^{\circ} \mathrm{C}$. The precursor is calcined at $450^{\circ} \mathrm{C}$ for $30 \mathrm{~min}$ to obtain nanoparticles of $\mathrm{ZnO}$. Finally, the solids are crushed to a fine powder using a mortar and pestle.

2.4. Solvothermal Synthesis of $\mathrm{ZnO}$ Nanoparticles. For the solvothermal synthesis of $\mathrm{ZnO}$ nanoparticles, $12 \mathrm{mmol}$ $\mathrm{Zn}\left(\mathrm{CH}_{3} \mathrm{COO}\right)_{2} \cdot 2 \mathrm{H}_{2} \mathrm{O}$ and $30 \mathrm{~mL}$ PEG-400 are dissolved in $150 \mathrm{~mL}$ absolute ethanol. The resulting mixture is transferred to a Teflon-lined stainless steel Parr 5521 high pressure compact laboratory reactor, together with $24 \mathrm{mmol}$ of solid $\mathrm{NaOH}$. The reactor is heated at a rate of $2^{\circ} \mathrm{C} / \mathrm{min}$ to $140^{\circ} \mathrm{C}$. After $24 \mathrm{~h}$, the autoclave is allowed to cool down naturally to room temperature. The precipitate is collected on a $0.1 \mu \mathrm{m}$ Supor-100 membrane filter, washed ten times with $20 \mathrm{~mL}$ of deionized water, and dried for $24 \mathrm{~h}$ in an oven at $60^{\circ} \mathrm{C}$. Finally, the solids are crushed to a fine powder using a mortar and pestle.

2.5. Characterization. The purity of the zinc-substituted aerosol OT is verified using inductively coupled plasmaatomic emission spectroscopy (ICP-AES, PerkinElmer 107 Optima 3000 DV). The thermal decomposition of the zinc oxalate precursor is studied by thermogravimetric analysis (TA Instruments TGA 951-2000). The powder is decomposed under a flow of dry air $(100 \mathrm{~mL} / \mathrm{min})$ and at a 
heating rate of $10^{\circ} \mathrm{C} / \mathrm{min}$. The crystal phase of the powders is determined using $\mathrm{X}$-ray diffraction (XRD) measurements, carried out on a Siemens D-5000 diffractometer (radiation: $\mathrm{Cu} \mathrm{K} \mathrm{al}_{1}$ ). Structural information of the intermediates and of the final products is obtained by Fourier transform infrared spectroscopy (Bruker IFS 66 FTIR spectrometer). For this purpose, $\mathrm{KBr}$ pellets are prepared, containing $1 \mathrm{wt} \%$ of the investigated product. To study the morphology of the products, a Philips CM 12 transmission electron microscope (TEM) is used. To this end, $10 \mathrm{mg}$ of the powder is first dispersed in $10 \mathrm{~mL}$ of methanol, then dropped on a coated grid (Formvar/Carbon $200 \mathrm{Mesh} \mathrm{Cu}$ ), and finally dried under an infrared light. Photon correlation spectroscopy (PCS) measurements (Brookhaven Instruments ZetaPALS) are carried out on the microemulsions and on diluted aqueous suspensions of the obtained powders $(0.1 \mathrm{mg} / \mathrm{mL})$. Before PCS measurements, the powder dispersions undergo an ultrasonic treatment for 5 min using a Branson Sonifier 250. Room temperature photoluminescence (PL) spectra between 360 and $650 \mathrm{~nm}$ are recorded on a FluoroLog (Horiba Jobin Yvon). The excitation wavelength is set at $335 \mathrm{~nm}$.

\section{Results and Discussion}

The procedure, described in Section 2.2, allows that sodium in aerosol OT is exchanged for zinc according to the following reaction:

$$
2 \mathrm{Na}(\mathrm{AOT})+\mathrm{Zn}\left(\mathrm{NO}_{3}\right)_{2} \longrightarrow \mathrm{Zn}(\mathrm{AOT})_{2}+2 \mathrm{NaNO}_{3}
$$

During washing, $\mathrm{NaNO}_{3}$ is removed, while $\mathrm{Zn}(\mathrm{AOT})_{2}$ remains in the organic fraction. Eastoe et al. [21] determined that for each $\mathrm{mol} \mathrm{Zn}(\mathrm{AOT})_{2}$ there is $6.5 \mathrm{~mol}$ water associated with the surfactant and/or the counterion, leading to a molar weight of $1026.6 \mathrm{~g} / \mathrm{mol}$. The zinc content of the zincsubstituted aerosol OT is verified using ICP-AES. The asdetermined zinc content is revealed to be $99.1 \%$ of the theoretical value. This is $21 \%$ higher than when we accurately followed the procedure of Eastoe. Performing the reaction at a higher temperature and for a longer period is consequently beneficial for the ion exchange.

Singhal et al. [22] are able to produce $\mathrm{ZnO}$ nanoparticles by using a microemulsion consisting of $\mathrm{Zn}(\mathrm{AOT})$, isooctane, and ethanol. Oxalic acid, in the form of a fine powder, was added to precipitate zinc oxalate. Finally, zinc oxide was produced after calcination of the oxalate. We unfortunately found that the addition of solid oxalic acid destabilizes the microemulsion. Consequently, the precipitation of zinc oxalate no longer takes place within the cores of micelles, resulting in large and irregularly shaped particles. A different approach is needed to ensure that zinc oxalate is formed in well-defined micelles.

This is realized by first establishing two separate microemulsions using the zinc-containing surfactant. One consisting of micelles enclosing an aqueous core, and in the other, microemulsion diethyl oxalate is situated in the centre of the micelles. When the two microemulsions are mixed, the micelles coalesce and their content are exchanged. As a

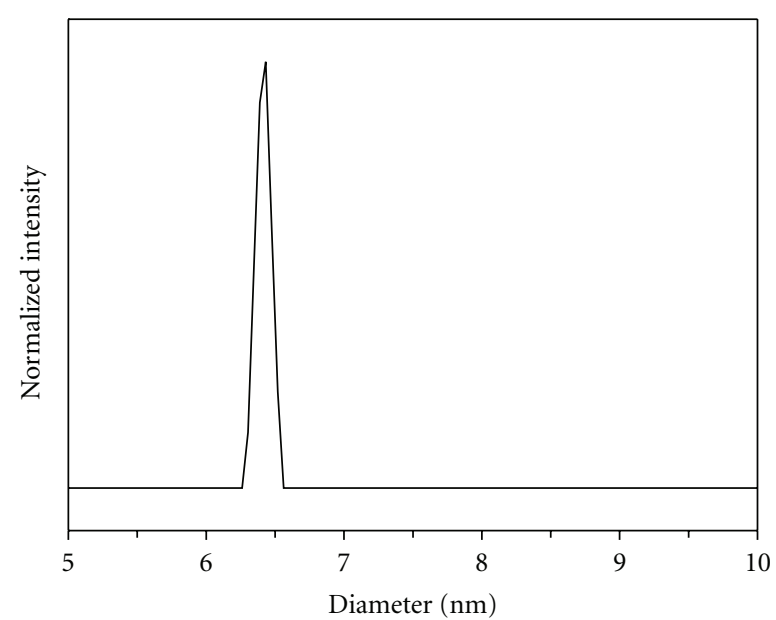

FIgURE 1: Size of the micelles in the mixed microemulsion as measured by photon correlation spectroscopy.

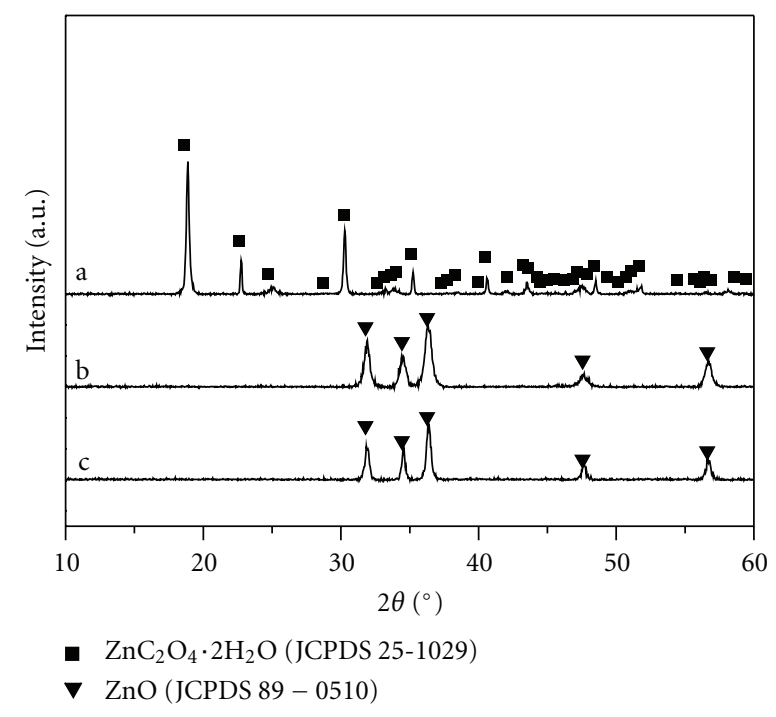

FIGURE 2: XRD patterns of the products obtained (a) from a microemulsion, before calcination, (b) from a microemulsion, after calcination, and (c) by a solvothermal method.

result, water and diethyl oxalate are combined. To obtain information on the size of the micelles, the mixture of the two microemulsions is examined with PCS. The result, shown in Figure 1, indicates that the micelles exhibit an average diameter of $6.7 \mathrm{~nm}$. The size distribution appears to be very narrow.

Upon heating, diethyl oxalate hydrolyzes to form oxalic acid and ethanol

$$
\begin{aligned}
\left(\mathrm{CH}_{3} \mathrm{CH}_{2}\right)_{2} \mathrm{C}_{2} \mathrm{O}_{4}+2 \mathrm{H}_{2} \mathrm{O} \longrightarrow & \mathrm{C}_{2} \mathrm{O}_{4}{ }^{2-}+2 \mathrm{H}^{+} \\
& +2 \mathrm{CH}_{3} \mathrm{CH}_{2} \mathrm{OH}
\end{aligned}
$$

The oxalate anions react with the $\mathrm{Zn}^{2+}$ ions from the $\mathrm{Zn}(\mathrm{AOT})_{2}$, and zinc oxalate is precipitated within the cores of micelles

$$
\mathrm{C}_{2} \mathrm{O}_{4}{ }^{2-}+\mathrm{Zn}^{2+}+2 \mathrm{H}_{2} \mathrm{O} \longrightarrow \mathrm{ZnC}_{2} \mathrm{O}_{4} \cdot 2 \mathrm{H}_{2} \mathrm{O}
$$




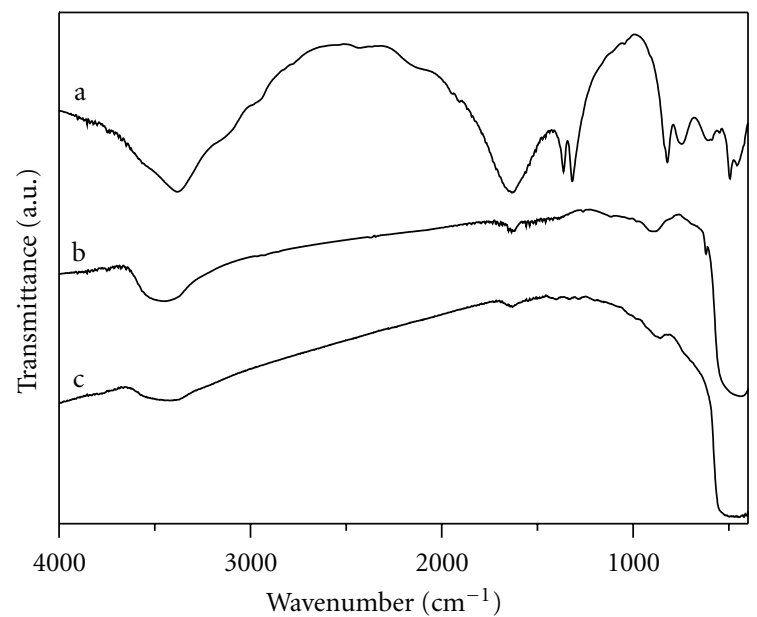

FIGURE 3: FTIR spectra of the products obtained (a) from a microemulsion, before calcination, (b) from a microemulsion, after calcination, and (c) by a solvothermal method.



Figure 4: Thermographic analysis of zinc oxalate, obtained from a microemulsion: (a) TGA-curve and (b) DTG-curve.

By adding acetone to the microemulsion, the micelles collapse, and their content is released. This allows the zinc oxalate nanoparticles to agglomerate, so they can be collected by centrifugation. The formation of zinc oxalate is confirmed by XRD analysis (Figure 2) and FTIR analysis (Figure 3) of the resulting powder. All the peaks in the XRD pattern can be assigned to zinc oxalate dihydrate (JCPDS: 251029). In the FTIR spectrum, zinc oxalate shows characteristic absorptions at $3380 \mathrm{~cm}^{-1}\left(\nu_{\mathrm{O}-\mathrm{H}}\right), 1630 \mathrm{~cm}^{-1}\left(\nu_{\mathrm{C}=\mathrm{O}}\right)$, $1365 \mathrm{~cm}^{-1}\left(\nu_{\mathrm{C}-\mathrm{O}}+\nu_{\mathrm{C}-\mathrm{C}}\right), 1300 \mathrm{~cm}^{-1}\left(\nu_{\mathrm{C}-\mathrm{O}}+\delta_{\mathrm{O}-\mathrm{C}=\mathrm{O}}\right)$, $825 \mathrm{~cm}^{-1}\left(\nu_{\mathrm{O}-\mathrm{Zn}-\mathrm{O}}\right), 740 \mathrm{~cm}^{-1}\left(\delta_{\mathrm{O}-\mathrm{C}=\mathrm{O}}+\nu_{\mathrm{Zn}-\mathrm{O}}\right), 610 \mathrm{~cm}^{-1}$ $\left(\nu_{\mathrm{O}-\mathrm{Zn}-\mathrm{O}}\right)$, and $490 \mathrm{~cm}^{-1}\left(\nu_{\mathrm{Zn}-\mathrm{O}}+\nu_{\mathrm{C}-\mathrm{C}}\right)[23]$.

Thermogravimetric analysis of the precipitate generates a curve that is distinctive for zinc oxalate dehydrate, [24] as presented in Figure 4 . In a first step, around $150^{\circ} \mathrm{C}$, water is released. The second weight loss at $400^{\circ} \mathrm{C}$ can be attributed to the oxidation of $\mathrm{ZnC}_{2} \mathrm{O}_{4}$ to $\mathrm{ZnO}$ and $\mathrm{CO}_{2}$. Calcination of the oxalate precursor at $450^{\circ} \mathrm{C}$ for $30 \mathrm{~min}$ consequently leads to the formation of $\mathrm{ZnO}$ nanoparticles. The occurrence of $\mathrm{ZnO}$ is verified by XRD and FTIR measurements. All the peaks in the XRD pattern (Figure 2) can be attributed to hexagonal, wurzite-type ZnO (JCPDS: 89-0510). In the FTIR spectrum (Figure 3), an intense absorption band below $600 \mathrm{~cm}^{-1}$ is explained by $\mathrm{Zn}-\mathrm{O}$ lattice vibrations. The broad band around $3500 \mathrm{~cm}^{-1}$ and the small peak at $1630 \mathrm{~cm}^{-1}$ indicate the presence of surface hydroxyl groups.

In the case of the solvothermal synthesis of zerodimensional $\mathrm{ZnO}$ nanoparticles, the dominant onedimensional growth of $\mathrm{ZnO}$ needs to be suppressed. This can be achieved by the intervention of additives. Here, PEG-400 is used, which can adsorb at the precipitating particles through hydrogen bonding with the $\mathrm{OH}$ groups on the $\mathrm{ZnO}$ surface [25]. As a result, growth units can no longer attach to the growing crystal faces. The XRD pattern of the solvothermally synthesized product is shown in Figure 2. It is apparent that the powder consists of a single $\mathrm{ZnO}$ phase (JCPDS: 89-0510). The FTIR spectrum of the solvothermally synthesized product is similar to the spectrum of the calcined powder (Figure 3). Zn-O lattice vibrations cause an intense absorption band below $600 \mathrm{~cm}^{-1}$. The presence of surface hydroxyl groups is indicated by the broad band around $3500 \mathrm{~cm}^{-1}$ and the small peak at $1630 \mathrm{~cm}^{-1}$. No peaks indicate the presence of PEG, demonstrating that washing removes the polymer sufficiently.

Figure 5 compares the TEM micrographs of the $\mathrm{ZnO}$ nanoparticles prepared by the microemulsion and the solvothermal method, respectively. The microemulsionmediated synthesis and subsequent calcination leads to dense aggregates, composed of primary particles with sizes in the range of 10 to $20 \mathrm{~nm}$. The applied heating profile for decomposing the zinc oxalate is most likely responsible for their aggregated state. In Figure 5, it is apparent that the solvothermal route leads to particles with a similar size distribution of 10 to $20 \mathrm{~nm}$ and an aspect ratio between 1 and 1.5. However, the aggregates that are observed in the calcined powder are in this case infrequent. This observation can be explained by the relatively mild synthesis conditions associated with the solvothermal technique.

This tendency to form larger and denser aggregates during calcination is further illustrated by the PCS measurements presented in Figure 6. For the solvothermal method, it can be observed that most entities exhibit sizes below $100 \mathrm{~nm}$. The dispersed powder obtained by the microemulsion/calcination route displays a much broader size distribution that starts at $400 \mathrm{~nm}$ and extends up to $750 \mathrm{~nm}$. Ultrasonification of the dispersion clearly is insufficient to break up the aggregates in this powder. Neither increasing the duty cycle of the sonifier nor the addition of a dispersant ( $50 \mu \mathrm{L}$ Darvan-C per $100 \mathrm{~mL}$ dispersion) proved to be adequate to decrease the size of the aggregates significantly. This is a clear indication that primary particles in the aggregates are strongly bonded together.

The optical properties of the powders reflect the electronic bandgap structure of zinc oxide. $\mathrm{ZnO}$ is a wide bandgap material $(3.4 \mathrm{eV})$ with a large exciton binding energy, suitable for effective UV emission. This can be seen in the photoluminescence spectra shown in Figure 7. The synthesized $\mathrm{ZnO}$ particles exhibit a sharp emission peak at $\sim 380 \mathrm{~nm}$ that results from the bandgap luminescence [26]. 




(a)

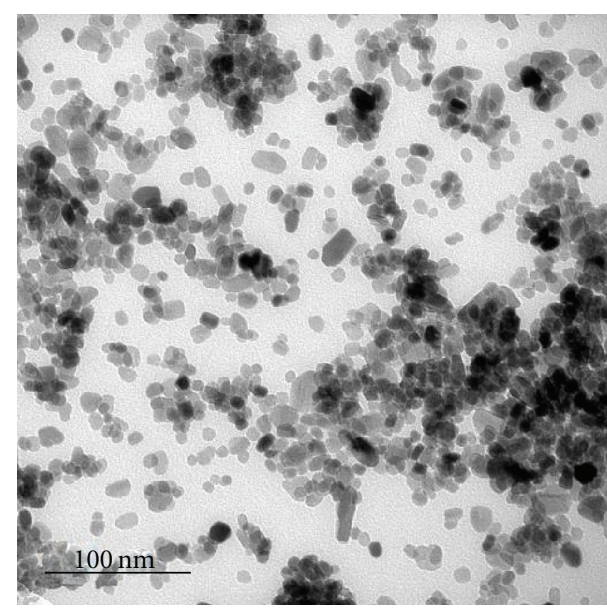

(b)

FIGURE 5: TEM micrographs of the zinc oxide nanoparticles synthesized (a) by a microemulsion-mediated method, after calcination and (b) by a solvothermal method.

This emission peak is clearly more intense in the case of the solvothermally synthesized product. Next to this UV luminescence, the photoluminescence spectra display in both cases a broad blue-green emission band. Although its exact nature is still controversial, the presence of this emission band is usually ascribed to recombination of electrons in singly occupied oxygen vacancies with photoexcited holes [27]. This emission is more intense for the powder, obtained by a microemulsion-mediated synthesis. The stronger UV luminescence and the weaker blue-green emission band are an indication of the better crystalline quality of the $\mathrm{ZnO}$ nanoparticles synthesized by means of the solvothermal method.

\section{Conclusion}

Quasispherical zinc oxide nanoparticles are successfully synthesized using (a) a PEG-assisted solvothermal method and (b) by the calcination of zinc oxalate obtained from

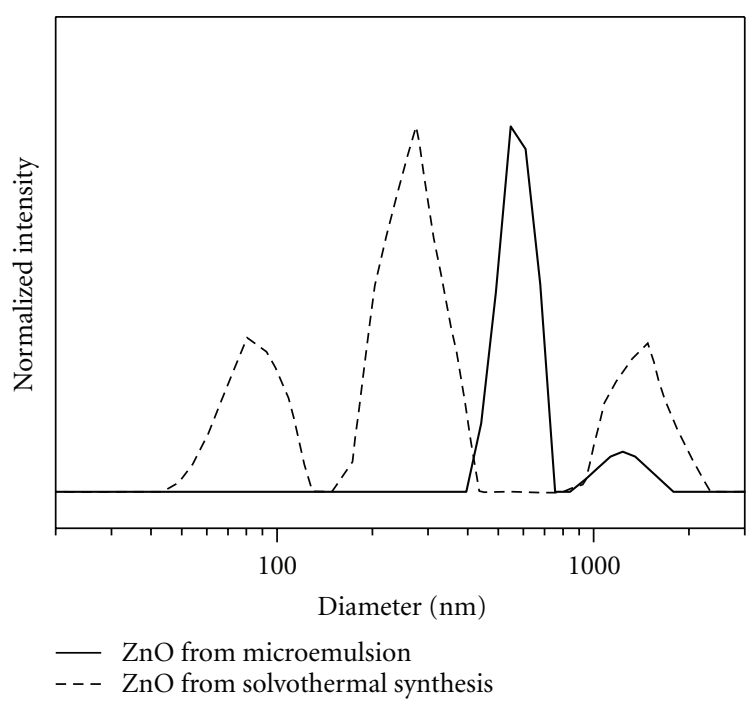

(a)



(b)

FIGURE 6: Comparison of the size distributions of the obtained $\mathrm{ZnO}$ powders as measured by photon correlation spectroscopy.

a microemulsion-mediated method. In the latter, zincsubstituted aerosol OT is used as a surfactant. The modified surfactant acts both as metal source and microemulsion stabilizer. Both synthesis techniques produce equiaxial nanoparticles with similar sizes in the range of 10 to $20 \mathrm{~nm}$. While the calcined powder shows rather large and dense aggregates, the mild conditions associated with the solvothermal technique allow the synthesis of nonagglomerated uniform $\mathrm{ZnO}$ particles. This observation is supported by TEM and PCS. The PL spectra of both powders show a peak at $380 \mathrm{~nm}$ and a broad blue-green emission band. The intense UV luminescence and the weaker blue-green emission of the $\mathrm{ZnO}$ nanoparticles synthesized by means of the solvothermal method band indicate a better crystalline quality of these nanoparticles. 


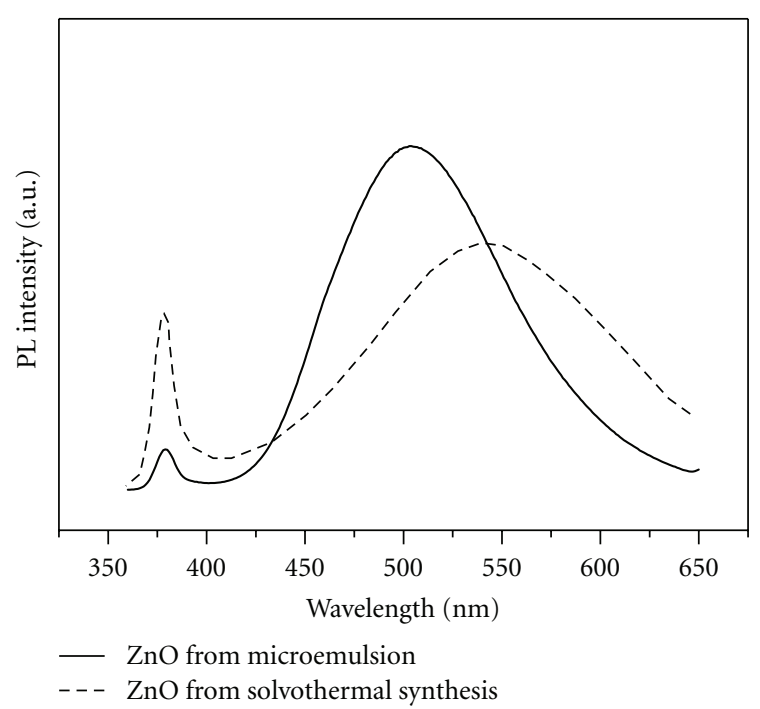

Figure 7: Comparison of the photoluminescence spectra of the obtained $\mathrm{ZnO}$ powders.

\section{Acknowledgments}

M. K. Van Bael and A. Hardy are postdoctoral fellows of the Fund for Scientific Research of Flanders (FWO Vlaanderen).

\section{References}

[1] Z. L. Wang, "Zinc oxide nanostructures: growth, properties and applications," Journal of Physics Condensed Matter, vol. 16, no. 25, pp. R829-R858, 2004.

[2] Z. Fan and J. G. Lu, "Zinc oxide nanostructures: synthesis and properties," Journal of Nanoscience and Nanotechnology, vol. 5, no. 10, pp. 1561-1573, 2005.

[3] Z. L. Wang, "Nanostructures of zinc oxide," Materials Today, vol. 7, no. 6, pp. 26-33, 2004.

[4] M. Grätzel, "Dye-sensitized solar cells," Journal of Photochemistry and Photobiology C, vol. 4, no. 2, pp. 145-153, 2003.

[5] W. J. E. Beek, M. M. Wienk, and R. A. J. Janssen, "Efficient hybrid solar cells from zinc oxide nanoparticles and a conjugated polymer," Advanced Materials, vol. 16, no. 12, pp. 1009-1013, 2004.

[6] H. Ohta and H. Hosono, "Transparent oxide optoelectronics," Materials Today, vol. 7, no. 6, pp. 42-51, 2004.

[7] V. K. Ivanov, A. S. Shaporev, F. Y. Sharikov, and A. Y. Baranchikov, "Hydrothermal and microwave-assisted synthesis of nanocrystalline $\mathrm{ZnO}$ photocatalysts," Superlattices and Microstructures, vol. 42, no. 1-6, pp. 421-424, 2007.

[8] M. Kursawe, R. Anselmann, V. Hilarius, and G. Pfaff, "Nanoparticles by wet chemical processing in commercial applications," Journal of Sol-Gel Science and Technology, vol. 33, no. 1, pp. 71-74, 2005.

[9] H. Van den Rul, M. K. Van Bael, A. Hardy, K. Van Werde, and J. Mullens, "Aqueous solution-based synthesis of nanostructured metal oxides," in Handbook of Nanoceramics and Their Based Nanodevices, H. S. Nalwa and T. Y. Tseng, Eds., American Scientific Publishers, Valencia, Calif, USA, 2009.

[10] H. Van Den Rul, D. Mondelaers, M. K. Van Bael, and J. Mullens, "Water-based wet chemical synthesis of (doped) $\mathrm{ZnO}$ nanostructures," Journal of Sol-Gel Science and Technology, vol. 39, no. 1, pp. 41-47, 2006.

[11] S. Hingorani, V. Pillai, P. Kumar, M. S. Multani, and D. O. Shah, "Microemulsion mediated synthesis of zinc-oxide nanoparticles for varistor studies," Materials Research Bulletin, vol. 28, no. 12, pp. 1303-1310, 1993.

[12] V. Degiorgio and M. Corti, Eds., Physics of Amphiphiles: Micelles, Vesicles and Microemulsions, Società Italiana di Fisica, Bologna, Italy, 1985.

[13] M. P. Pileni, "The role of soft colloidal templates in controlling the size and shape of inorganic nanocrystals," Nature Materials, vol. 2, no. 3, pp. 145-150, 2003.

[14] M. Lal, V. Chhabra, P. Ayyub, and A. Maitra, "Preparation and characterization of ultrafine $\mathrm{TiO}_{2}$ particles in reverse micelles by hydrolysis of titanium di-ethylhexyl sulfosuccinate," Journal of Materials Research, vol. 13, no. 5, pp. 1249-1254, 1998.

[15] V. Chhabra, M. Lal, A. N. Maitra, and P. Ayyub, "Nanophase $\mathrm{BaFe}_{12} \mathrm{O}_{19}$ synthesized from a nonaqueous microemulsion with $\mathrm{Ba}$ - and Fe-containing surfactants," Journal of Materials Research, vol. 10, no. 11, pp. 2689-2692, 1995.

[16] W. J. Li, E. W. Shi, W. Z. Zhong, and Z. W. Yin, "Growth mechanism and growth habit of oxide crystals," Journal of Crystal Growth, vol. 203, no. 1, pp. 186-196, 1999.

[17] K. Elen, M. K. Van Bael, H. Van Den Rul, J. D'Haen, and J. Mullens, "Additive-free hydrothermal synthesis of high aspect ratio $\mathrm{ZnO}$ particles from aqueous solution," Chemistry Letters, vol. 35, no. 12, pp. 1420-1421, 2006.

[18] K. Elen, H. Van Den Rul, A. Hardy et al., "Hydrothermal synthesis of $\mathrm{ZnO}$ nanorods: a statistical determination of the significant parameters in view of reducingthe diameter," Nanotechnology, vol. 20, no. 5, Article ID 055608, 2009.

[19] Z. Li, Y. Xiong, and Y. Xie, "Selected-control synthesis of ZnO nanowires and nanorods via a PEG-assisted route," Inorganic Chemistry, vol. 42, no. 24, pp. 8105-8109, 2003.

[20] Y. Zhang and J. Mu, "Controllable synthesis of flower- and rod-like $\mathrm{ZnO}$ nanostructures by simply tuning the ratio of sodium hydroxide to zinc acetate," Nanotechnology, vol. 18, no. 7, Article ID 075606, 2007.

[21] J. Eastoe, G. Fragneto, B. H. Robinson, T. F. Towey, R. K. Heenan, and F. J. Leng, "Variation of surfactant counterion and its effect on the structure and properties of Aerosol-OTbased water-in-oil microemulsions," Journal of the Chemical Society, Faraday Transactions, vol. 88, no. 3, pp. 461-471, 1992.

[22] M. Singhal, V. Chhabra, P. Kang, and D. O. Shah, "Synthesis of $\mathrm{ZnO}$ nanoparticles for varistor application using $\mathrm{Zn}$ substituted aerosol OT microemulsion," Materials Research Bulletin, vol. 32, no. 2, pp. 239-247, 1997.

[23] K. Nakamoto, Infrared Spectra of Inorganic and Coordination Compounds, Wiley-Interscience, New York, NY, USA, 1970.

[24] T. Ahmad, S. Vaidya, N. Sarkar, S. Ghosh, and A. K. Ganguli, "Zinc oxalate nanorods: a convenient precursor to uniform nanoparticles of ZnO," Nanotechnology, vol. 17, no. 5, pp. 1236-1240, 2006.

[25] S. Liufu, H. Xiao, and Y. Li, "Investigation of PEG adsorption on the surface of zinc oxide nanoparticles," Powder Technology, vol. 145, no. 1, pp. 20-24, 2004.

[26] L. Guo, S. Yang, C. Yang et al., "Synthesis and characterization of poly(vinylpyrrolidone)-modified zinc oxide nanoparticles," Chemistry of Materials, vol. 12, no. 8, pp. 2268-2274, 2000.

[27] J. Zhang, L. Sun, J. Yin, H. Su, C. Liao, and C. Yan, "Control of $\mathrm{ZnO}$ morphology via a simple solution route," Chemistry of Materials, vol. 14, no. 10, pp. 4172-4177, 2002. 

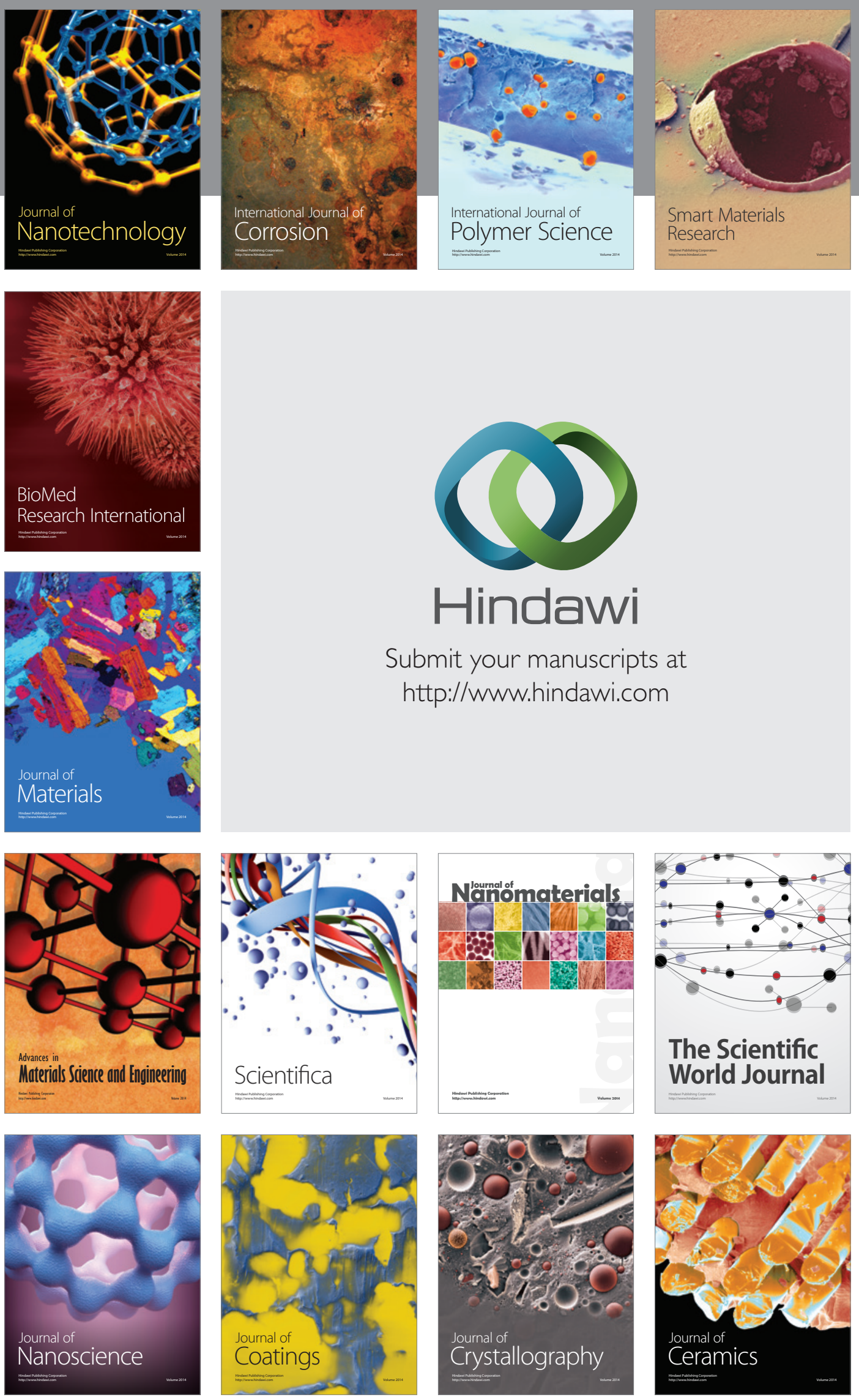

The Scientific World Journal

Submit your manuscripts at

http://www.hindawi.com

\section{World Journal}

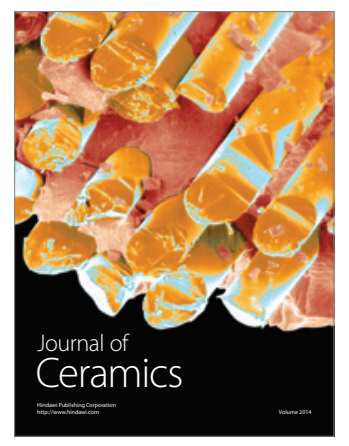

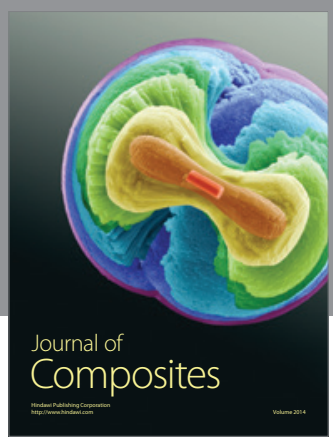
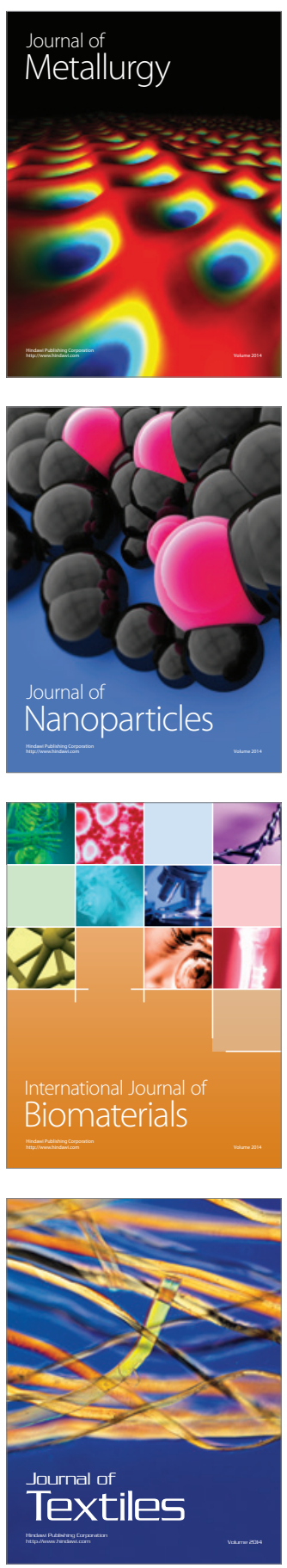